\title{
Smoke Support System Simulation Effectiveness Evaluation
}

\author{
Cheng Cui, Xuezheng Zhu, Xun Sun ${ }^{\text {, }}$ Kunlin Nie ${ }^{\text {b }}$, Yankui Li \\ Institute of NBC Defence of the PLA, Beijing, 102205, China \\ a sunxun2373@163.com, bemail542112706@qq.com
}

Keywords: Smoke Support; Operation Simulation; Effectiveness Evaluation

\begin{abstract}
Establish two class operational effectiveness evaluation index system of smoke support system, and based on classic smoke support operational scenario, according to system simulation method, conduct program inferring and deducting and evaluate smoke operational effectiveness by integrating it into full battlefield environment. Inside battlefield operation counter system, evaluate special extent of different operational concept plan influencing full operation system, provide commanders with intellectual decision, and master the application opporunity and means of smoke support system.
\end{abstract}

\section{Introduction}

Operational effectiveness of smoke support system is very outstanding, and will have important smoke support function in the future operation. To evaluate operational effectiveness of smoke support system, integrating the system into battlefield countermeasure system is needed, and evaluation is conducted aiming at special tasks and environment conditions. Operation under information condition in the future is countermeasure between operational systems under special battlefield environment, namely countermeasure of operational system full operational capability[1]. In the simulation of counter system, we can establish simulation models according to the operational characteristics of weapon equipment system in the operational scenario requirements or design plan, and integrate these models into battlefield environment in order to evaluate operational effectiveness. Main methods used to evaluate equipment system effectiveness include method of operation simulation, method of exploration analysis, method of integrating discussion and so on. Method of operation simulation is indispensable for evaluating equipment system effectiveness.

We can use the method of operation simulation to evaluate operational effectiveness of smoke support system. Based on using computer program to simulate military equipment system countermeasures, operation unit and multi- dimensional battlefield environment, by inferring and deducting according to designed program, all the factors which constitute combat capability and main relationships between friend and foe is linked with mathematical equations, and the question' approximation is calculated by computer. Acquire all kinds of statistical data, research and evaluate operational effectiveness of smoke support system under different operational scenario conditions and same battlefield conditions, and evaluate influence on integral operational system with smoke support system.

\section{Operational scenario}

We use modeling and simulation method to evaluate operational effectiveness of smoke support system mainly based on mechanized infantry offensive combat scenario. The key points mainly include simulation battlefield environment, simulation combat operation and operational effectiveness evaluation. According to requirements, battlefield forces is disassembled into individual soldier, material are classified into single equipment and time step size is $1 \mathrm{~s}$, and combat operation is divided into four stages of occupating deployment area, storming assault, passing through enemy' barrier and inbursting enemy' position.

We consider the scenario of mechanized infantry offensive combat in fortified position in order to evaluate effectiveness of three operational concept plans whether red forces have smoke support 
system and research the function of smoke support system in operation of offens and defense.

Operational concept plans are as follows.

The basic scenario of mechanized infantry offensive combat in fortified position is involved with hilly land in certain area, as shown in Fig.1. The basic situation is that blue forces is failed during iteratively contesting the first line defense position with red landing forces, but they hold defense position in depth. In order to disintegrate the enemy depth defense system as quickly as possible, campaign leaders decide to integrate offense with counter, use elite troops to assault priorly, and achieve overwhelming victory of landing operation. Our corps act as left wine front attack group in the higher echelon organizations[4].

The application of smoke support system directly influences the outcome of ultimate operation. Commanders need to select the optimum plan in the following three operational concept plans. While completing tasks assigned by higher echelon within the prescribed period of time, commanders must make person casuslty and equipment destruction minimum.

Plan 1: Directly conduct storming assault without smoke support after artillery attacked. The basic offensive stages will be consist of occupating deployment area, storming assault, passing through enemy' barrier and inbursting enemy' position.

Plan 2: Respectively produce smoke 2 minutes during three different stages of occupating deployment area, storming assault and passing through enemy' barrier. The basic offensive stages will be consist of occupating deployment area(producing smoke 2 minutes), storming assault(producing smoke 2 minutes), passing through enemy' barrier(producing smoke 2 minutes) and inbursting enemy' position.

Plan 3: After artillery attacked, while storming assault smoke support system produce offensive shield smoke 6 minutes. The basic offensive stages will be consist of occupating deployment area, storming assault(producing smoke 6 minutes), passing through enemy' barrier(sustained smoke ) and inbursting enemy' position.

\section{Evaluation index system for smoke support system supporting offensive operational concept plans}

By analyzing the tasks and intents of operational scenario, we can obtain that:

(1)It is most important for analyzing the operational concept plans to complete tasks. Determine whether the task $\mathrm{P}$ is completed, 1 for being completed within the prescribed period of time, and 0 for not being completed within the prescribed period of time. Establish simulation models taking our offensive unit for example.

(2)The capabilities of occupying and controlling position of friend and foe: $\mathrm{V}$ is average offensive velocity, and $\mathrm{T}$ is time needed to complete task.

(3)Casualty case: the casualty ratio of red forces or blue forces.

$$
\begin{aligned}
R_{p} & =\frac{\text { the reds numbers of casualties }}{\text { the reds total number of staff }} \quad R_{e}=\frac{\text { the numbers of reds damage equipment }}{\text { the total number of reds equipment }} \\
B_{p} & =\frac{\text { the blues numbers of casualties }}{\text { the blues total number of staff }} \quad B_{e}=\frac{\text { the numbers of blues damage equipment }}{\text { thetotal numberof blues equipment }}
\end{aligned}
$$

(4)Resource consumption: ammunition consumption of red forces or blue forces ${ }^{R_{a}, B_{a}}$.

Within the smoke support system, first class evaluation index mainly include degree of task completion, time-space effectiveness, casualty ratio and resource consumption, and second class evaluation index include average offensive velocity, time needed to complete task, casualty ratio of red forces, casualty ratio of blue forces, ammunition consumption of red forces and ammunition consumption of blue forces, as shown in Fig.1. 


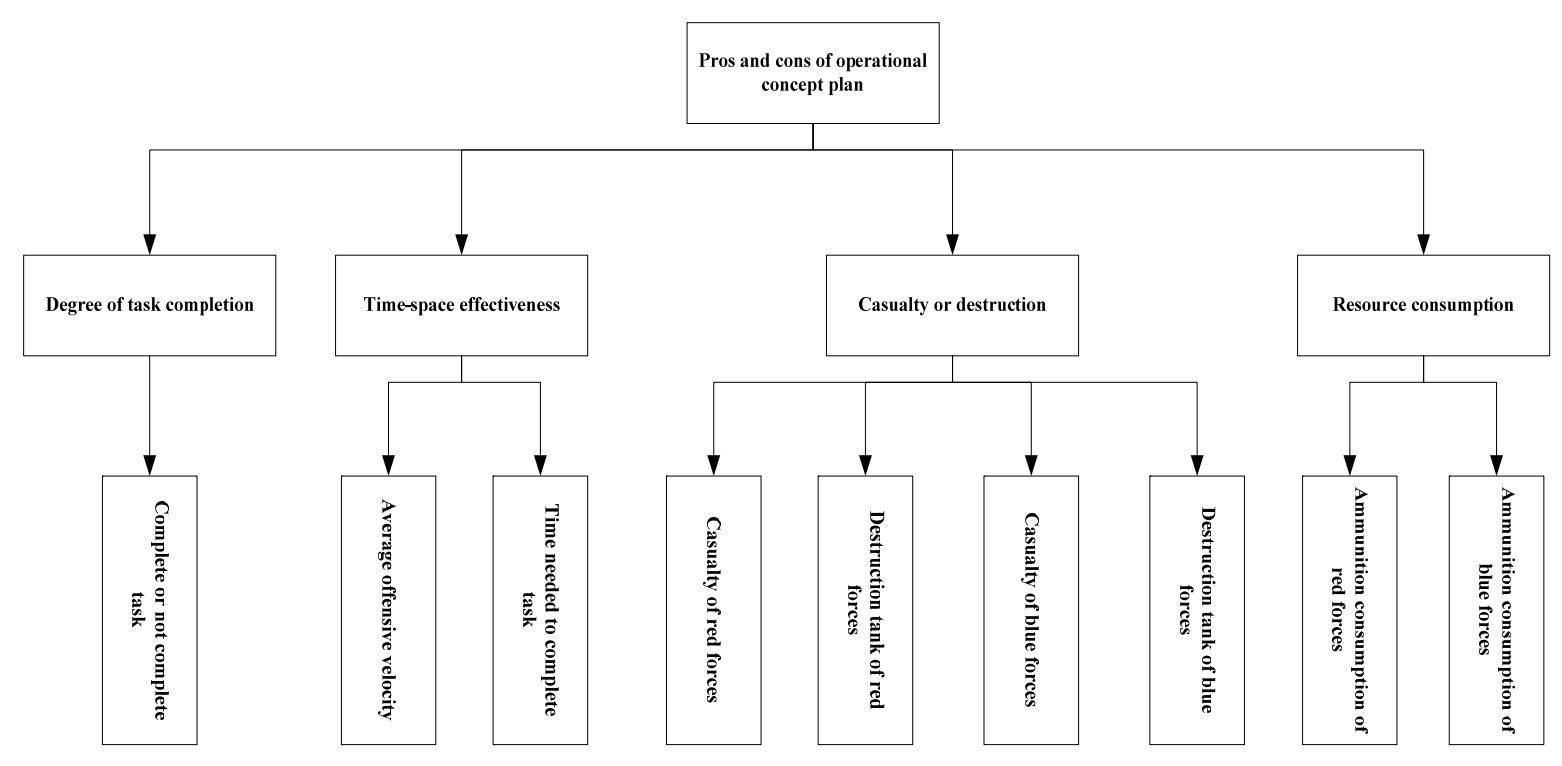

Figure 1. Evaluation index system of operational concept plan

\section{Battlefield combat countermeasure system simulation}

Operational effectiveness evaluation of smoke support system must consider counter conditions and operational target, and coordination between all kind of weapons, for example, coordination between smoke support system and mechanized infantry or tank corps. We must also consider the performance of operational effectiveness during full operational process and effectiveness difference in the different scale operation. In a word, if we want to evaluate effectively operational effectiveness evaluation of smoke support system, we must consider special operational environment and force organization under counter conditions.

Being used to evaluate operational effectiveness evaluation of smoke support system, the method of operation simulation can save time and expense, reflect counter conditions and operational target, and consider the coordination between our corps weapons and the performance of operational effectiveness during full operational process.

In order to meet requirements of operational effectiveness evaluation of weapon system, we must determine the structure of battlefield counter system, and accordingly establish structure models of battlefield counter system.

The structure models of battlefield counter system mainly depict the relationships of assembly, command and coordination between different elements within the same operational concept plan, and the relationships of detection, reconnaissance and countermeasure between different elements within hostility operational concept plan.

Generally, the method of establishing battlefield counter system application structure is as follows. According to informations such as military mission, event, evaluation index, forces, constraint and operational area, determine models, assembly and equipment which must be involved with the simulation scenario, and furtherly determine the functions of equipment and personnel. According to the degree of supporting military operation function, determine forces, equipment and personnel, and select assembly and model which are compatible each other ${ }^{[4]}$.

During the simulation, multi-layer and multi-orientation disassemble is conducted, mainly including forces disassemble, material classifying, time discrete and combat operation disassemble. According to requirements, battlefield forces is disassembled into individual soldier, material are classified into single equipment and time step size is $1 \mathrm{~s}$, and combat operation is divided into four stages of occupating deployment area, storming assault, passing through enemy' barrier and inbursting enemy' position.

\section{Battlefield environment simulation}

Battlefield environment is mainly acquired by establishing models according to operational 
scenario map, including nature environment model, artificial environment model, personnel and equipment model, and special effectiveness etc. For example, tank, armored car, individual soldier marching on the ground; artillery attack and plane bombing; and the change of rain, snow, fog and so on.

\section{Combat operation simulation}

1) System boundary

Because research intention of combat simulation is to evaluate operational effectiveness of smoke support system, system design must be developed closely considering smoke support weapon sysem.

In order to emphasize the main contradiction and provide necessary support to mission simulation, the convention and index of system boundary for combat simulation are as follows.

(1)Offense and defense system of tank vs tank

Al: Hit probability of tank vs tank under counter conditions, including stationery tank vs stationery tank, movable tank vs stationery tank, stationery tank vs movable tank, and movable tank vs movable tank.

A2: Hit probability of tank vs tank under smoke shield conditions.

Other syetems such as offense and defense system of tank vs armored car, counter system of antitank guided missile vs tank, and counter system of antitank guided missile vs armored car are similar with offense and defense system of tank vs tank, needless to say in this article.

(2) Offense and defense system of tank vs armored car

(3) Counter system of antitank guided missile vs tank

(4) Counter system of antitank guided missile vs armored car

The key points of smoke support system combat operation simulation mainly include three aspects of generating battlefield environment, simulating combat operation and evaluating operational effectiveness. Battlefield environment is mainly acquired by establishing models according to operational scenario map. Simulating combat operation is disassembled into four stages.

2) Structure model

(1)Basic functions

This model provide target detection probability, time of detection, acquired target coordinate value, hit probability, target threat assessment of the system and battlefield situation analysis, and optimize to distribute weapons over the targets that meet threat conditions.

Main factors include:

Velocity characteristics of antitank guided missile;

Range of antitank guided missile;

Maneuver characteristics of antitank guided missile;

Velocity characteristics of tank shell;

Maneuver characteristics of tank during different offensive stages;

Range of tank during different offensive stages;

Maneuver characteristics of armored car during different offensive stages;

Range of armored car during different offensive stages.

(2) External interfaces

Antitank guided missile model: input port, coordinates of antitank guided missile, velocity information, range, hit probability;

Tank model: input port, coordinates of tank, velocity information, range, hit probability;

Armored car model: input port, coordinates of armored car, velocity information, range, hit probability;

Infantry model: input port, coordinates of infantry, velocity information, range, hit probability.

(3) Internal structure

The system model include some modules such as position solution, hit assessment and so on. The relationships between modules is basically serial, but not changeless. We can achieve different functions of model according to different equipment and shell, and using corresponding module to assemble. 


\section{3) Entity status}

We use status variability to depict the status of every basic combat unit on the battlefield at any moment. Assume there are $\mathrm{M}$ basic combat unit on the battlefield, and the status of unit $\mathrm{k}$ at moment $\mathrm{t}$ is $\mathrm{Xk}(\mathrm{t})\{\mathrm{Xk}(\mathrm{t}), \mathrm{k}=1,2, \ldots, \mathrm{M} ; \mathrm{t} \geq 0\}$ which is often multidimensional random process called status process. Every component of the status process is one status variability of basic combat unit. The expectation value of the status process at end moment te is $\operatorname{EXk}(\mathrm{te})(\mathrm{k}=1,2, \ldots, \mathrm{M})$, which is just output result what simulation concerns ${ }^{[6]}$.

\section{Mathematical model}

1) Destruction probability of red forces tank

$$
\begin{aligned}
& m_{-} b_{-} R_{\text {Tank }}[i]=\sum_{l=1}^{3}\left(\sum_{i=1}^{N[l]} B_{\text {TankP }}[l][j]+\sum_{i=1}^{M[l]} B_{\text {AntiTankP }}[l][k]\right) \\
& B_{\text {TankP }}[l][j]=f\left(\operatorname{Dis} \tan c e\left(R_{(x, y)}, B_{(x, y)}\right), m_{-} V_{\text {Tank }}[i], t, \lambda\right) \\
& B_{\text {AntiTankP }}[l][k]=f\left(\operatorname{Dis} \tan c e\left(R_{(x, y)}, B_{(x, y)}\right), m_{-} V_{\text {Tank }}[i], t, \lambda\right)
\end{aligned}
$$

where, $m_{-} b_{-} R_{\text {Tank }}[i]$ means whether the red forces tank $i$ is hit, being a bool variability;

$B_{\text {Tank }}[I][j]$ is the hit probability of the blue forces tank $\mathrm{j}$ at moment $\mathrm{t}$ during the first stage;

$B_{\text {Antitank } R}[][k]$ is the hit probability of the blue forces tank $\mathrm{k}$ during the first stage;

$\mathrm{N}[1]$ is number of the fired tank shell during the first stage;

$\mathrm{M}[1]$ is number of the fired antitank guided missile during the first stage;

1 is one offensive stage. 1, 2, 3 offensive stage are divided.

Dis $\tan c e\left(R_{(x, y)}, B_{(x, y)}\right)$ is the distance of red forces equipment apart from blue forces equipment at moment t;

$m_{-} V_{\text {Tank }}[i]$ is the velocity of red forces equipment at moment $t$;

$\lambda$ is influence factor of smoke to hit probability.

Destruciton probability of blue forces tank, blue forces armored car and red forces armored car are similar, needless to say in this article.

2) Survival probability of red forces antitank guided missile group

By referring correlative documents, we fonud the prelaunch survival probability of red forces antitank guided missile group is about 0.85 before tank is detected. Referring former Soviet union motorized rifle division offensive campaign scenario, we found they specially emphasized suppressing antitank weapons and thought tank offensive velocity lies on effectively suppressing opposite artillery and antitank guided missile at front support position. So after diamounted maneuver, group faced themselves survival capabilities problem. Usually, artillery preparation consists of several storming raid, and the fire of the first raid and the last raid is most strongest. According to the calculation with antitank weapon depth $600 \mathrm{~m}$, on the assumption that group is destroyed when suffer from artillery attack inside $25 \mathrm{~m}$ around group, the prelaunch survival probability of red forces antitank guided missile group is about 0.5 before tank is detected.

$$
\begin{aligned}
& \mathrm{P}=\left(1-\Delta \mathrm{S}_{1} / \Delta \mathrm{S}_{2}\right)^{\mathrm{N}} \\
& \mathrm{N}=0.5\left(\mathrm{t}_{\text {on foot }}+\Delta \mathrm{t}+\mathrm{t}_{\text {expand }}\right)^{\mathrm{N}} \\
& \Delta t=3.53 \times \mathrm{e}^{0.1136 \mathrm{G}} \\
& \text { where, } \Delta t \text { increase time }(\mathrm{s}) \text {, compared with not carrying weapons; } \\
& \mathrm{N} \longrightarrow \text { total number of blue forces artillery per km pressing area during prelaunch time } \mathrm{t} ; \\
& \Delta \mathrm{S}_{1} \longrightarrow \text { area of effectively destroying group with single artillery; } \\
& \Delta \mathrm{S}_{2} \longrightarrow \text { area of per km pressing area }
\end{aligned}
$$

3) Simulation process

According to operation doctrine, if loss rate of the offensive side is more than $50 \%$, corps will lose offensive operation capability; if loss rate the defensive side is more than $60 \%$, corps will lose defensive operation capability. In the experiment, according to the simulation result, if any side lose operation capability, system will be terminated automatically by computer. The simulation process is shown in Fig.2. 


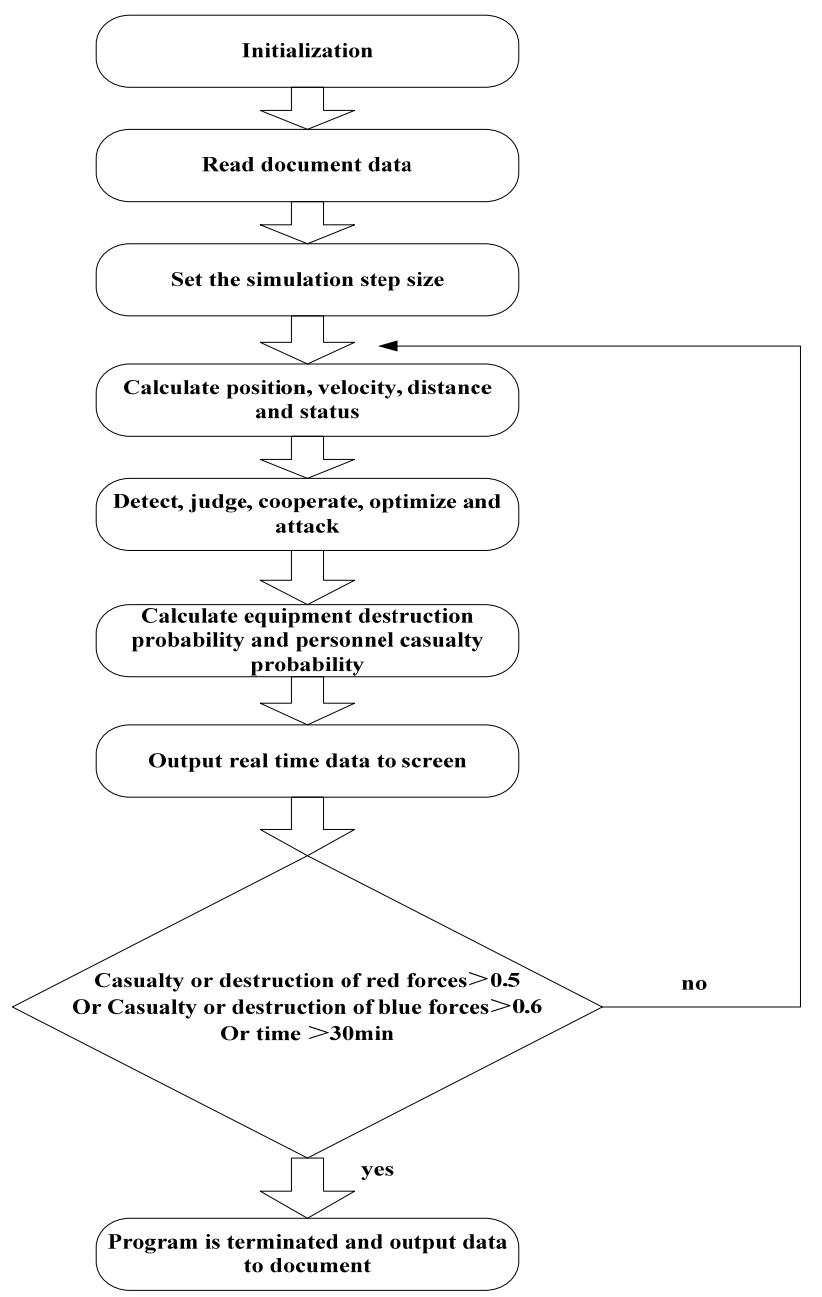

\section{Simulation results of evaluation index}

Figure 2. Simulation process

After simulating one thoundred times, simulation results of evaluation index on 3 kinds of operational concept plan are shown in Table 1.

Table 1. Simulation results of evaluation index on 3 kinds of operational concept plan

\begin{tabular}{|c|c|c|c|c|c|c|c|c|c|}
\hline & & \multicolumn{2}{|c|}{$\begin{array}{c}\text { Time-space } \\
\text { effectiveness }\end{array}$} & \multicolumn{4}{|c|}{ Casualty or destruction } & \multicolumn{3}{c|}{ Resource consumption } \\
\cline { 2 - 10 } plan & $\begin{array}{c}\text { Degree of } \\
\text { task } \\
\text { completion }\end{array}$ & $\begin{array}{c}\text { Average } \\
\text { velocity } \\
(\mathrm{km} / \mathrm{h})\end{array}$ & $\begin{array}{c}\text { time } \\
(\mathrm{min})\end{array}$ & $\begin{array}{c}\text { Vehicle } \\
\text { destruction } \\
\text { ratio of } \\
\text { red forces } \\
(\%)\end{array}$ & $\begin{array}{c}\text { Personnel } \\
\text { casualty } \\
\text { ratio of } \\
\text { red forces } \\
(\%)\end{array}$ & $\begin{array}{c}\text { Vehicle } \\
\text { destruction } \\
\text { ratio of blue } \\
\text { forces }(\%)\end{array}$ & $\begin{array}{c}\text { Personnel } \\
\text { casualty } \\
\text { ratio of } \\
\text { blue } \\
\text { forces } \\
(\%)\end{array}$ & $\begin{array}{c}\text { Ammunition } \\
\text { consumption } \\
\text { of red } \\
\text { forces } \\
\text { (artillery) }\end{array}$ & $\begin{array}{c}\text { Ammunition } \\
\text { consumption } \\
\text { of blue } \\
\text { forces } \\
(\text { artillery })\end{array}$ \\
\hline $1^{\circ}$ & 1 & 20 & 20 & 41.9 & 44.9 & 60 & 55.3 & 16 & 25 \\
\hline $2^{\circ}$ & 1 & 20.7 & 19.5 & 19.4 & 22.9 & 60 & 55.3 & 25 & 24 \\
\hline $3^{\circ}$ & 1 & 21.4 & 19 & 16.1 & 12.3 & 60 & 23.7 & 35 & 25 \\
\hline
\end{tabular}

Note 1: ammunition consumption only consider tank shell and antitank guided missile.

\section{AHP evaluation model}

We use layer analysis method to evaluate the effectiveness of smoke generator system, mainly by contrasting three plans. The first plan is involved with operational effectiveness without using smoke. The second plan is divided into three stages, and every stage is involved with operational effectiveness with using 2 minuts smoke. The third plan is involved with operational effectiveness with continuously using 6 minutes smoke.

1) Uniformity of evaluation index types

By analyzing, we found evaluation index system of operational concept plan comprises two types index of maximum index and minimum index.As far as the evaluation of operational concept plan is 
concerned, the index such as degree of task completion, average offensive velocity, casualty ratio of blue forces, ammunition consumption of blue forces and so on is bigger, effectiveness is better. On the contrary, the index such as time needed to complete task, casualty ratio of red forces, ammunition consumption of red forces and so on is smaller, effectiveness is better. So, we must uniformise the evaluation index types before integral evaluation is conducted.

For minimum index, direct

$$
x^{*}=\frac{1}{x}
$$

By processing, three indexes of time needed to complete task, casualty ratio of red forces, ammunition consumption of red forces are converted into maximum index.

2) Dimensionless of evaluation index

In the evaluation index of operational concept plan, the value of degree of task completion is 1 or 0 ; the dimension of average offensive velocity is $\mathrm{m} / \mathrm{s}$; the dimension of time needed to complete task is minute; the dimension of red forces casualty and blue forces casualty is personnel and equipment; the dimension of ammunition consumption of red forces and blue forces is artillery. In order to reflect practice as far as possible, exclude the influence because of different dimension and different order of magnitudes and avoid irrational phenomenon, we must make the evaluation index dimensionless. In this article, we adopt normalization processing method.

For concerned index $x j(j=1,2,3 \ldots)$, its value is $\{x i j \mid i=1,2,3 \ldots ; j=1,2,3 \ldots\}$.

$$
x *_{i j}=\frac{x_{i j}}{\sum_{i=1}^{n} x_{i j}}
$$

3) Data processing

Firstly, we use uniformity and dimensionless to preprocess three groups of data respectively.

Acquire data

$\left(\begin{array}{lllllllll}0.33 & 0.32 & 0.32 & 0.17 & 0.15 & 0.38 & 0.41 & 0.52 & 0.33 \\ 0.33 & 0.33 & 0.33 & 0.37 & 0.29 & 0.38 & 0.41 & 0.28 & 0.32 \\ 0.33 & 0.34 & 0.34 & 0.45 & 0.55 & 0.23 & 0.18 & 0.19 & 0.34\end{array}\right)$

4) Weight judgment

By using expert scoring method, we use judgment matrix to calculate weight. For below second class index, we use expert of set-valued iteration method to judge.

Firstly construct two-two judement matrix. Two-two contrast is conducted for four indexes of task completion a, time-space effectiveness $\mathrm{b}$, casualty $\mathrm{c}$, and resource consumption $\mathrm{d}$.

$$
A=\left[\begin{array}{cccc}
1 & \frac{1}{3} & \frac{1}{5} & \frac{1}{7} \\
3 & 1 & \frac{1}{2} & \frac{1}{3} \\
5 & 2 & 1 & \frac{1}{2} \\
7 & \frac{1}{3} & 2 & 1
\end{array}\right]
$$

The weight vector of every layer single row of judgment matrix is $\mathrm{W}=(0.124,0.586,0.218,0.012)$ $\mathrm{T}$, the biggest characteristic root $\lambda \max =4.02, \mathrm{CL}=0.007$, look-up table to $\mathrm{RI}=0.89$, so $\mathrm{CR}=0.08<0.1$. Obviously, the judgment matrix meet uniformity requirement.

5) Calculation of evaluation results

$\mathrm{E} 1=0.285 ; \mathrm{E} 2=0.315 ; \mathrm{E} 3=0.339$ 。

The score order is $3^{\circ}>2^{\circ}>1^{\circ}$, so the plan $3^{\circ}$ score is most.

\section{Conclusion}

Comparing evaluation results with Table 1, we can find although plan 1, plan 2 and plan 3 all completed tasks, the vehicle destruction ratio in plan $1(41.9 \%)$ is more higher than plan $2(19.4 \%)$ or plan $3(16.1 \%)$; the personnel casualty ratio in plan $1(44.9 \%)$ is more higher than plan $2(22.9 \%)$ or plan 
$3(12.3 \%)$; the offensive velocity in plan $1(20 \mathrm{~km} / \mathrm{h})$ is more lower than plan $2(20.7 \mathrm{~km} / \mathrm{h})$ or plan $3(21.4 \mathrm{~km} / \mathrm{h})$; In terms of offensive time, plan 1 is more lower than plan 2 or plan 3; only one index of ammunition consumption of red forces in plan 1 is more lower than plan 2 or plan 3. Plan 2 and plan 3 all used smoke, and we can find the vehicle destruction ratio in plan 2(19.4\%) is more higher than plan $3(16.1 \%)$; the personnel casualty ratio in plan $2(22.9 \%)$ is more higher than plan $3(12.3 \%)$; the offensive velocity in plan $2(20.7 \mathrm{~km} / \mathrm{h})$ is more lower than plan $3(21.4 \mathrm{~km} / \mathrm{h})$; In terms of offensive time, plan 2 is more lower than plan 3; the vehicle destruction ratio and personnel casualty ratio of blue forces in plan 2 is more higher than plan 3; the ammunition consumption of red forces in plan 2 is more lower than plan 3. Through the above analysis and integrating the results of layer analysis method, we can obtain the conclusion.

Smoke support system is an important part of full operation, and using the system in operation can greatly enhance the operational effectiveness of force. Based on the assumption, when using smoke support system to support our corps to conduct offensive operation, the effectiveness of continuously produing smoke is best. When making a decision, we must specially evaluate special extent of different operational concept plan influencing full operation system, and master the application opporunity and means of smoke support system.

\section{References}

[1] Feng Yang, Study on Inter-hierarchy Modeling Approach in Weapon-Platform Level System-of-systems Combat Simulation for Operational Effectiveness Evaluation[D], Changsha. National University of Defense Technology, 2003

[2] Science Application International Corporation, Model Based Simulation Composition System Architecture Report, 1998

[3] Introduction to modeling and simulation on system of system (SoS) encounter[M], Beijng, National University of Defense Press, 2009.07

[4] Qisheng Guo, System Effectiveness Evaluation[M], Beijng, National Defence Industrial Press, 2005.

[5] Xingtang Liu, Theory, method and technology of complex system[M], Beijng. Science Press, 2008. 